\title{
Outcome of Instrumental Vaginal Delivery at Patan Hospital
}

\section{Basant Lamichhane}

Rapti Acedemy of Health Sciences, Dang.

Received: 20 October 2018; Accepted: 12 December 2018

DOI: 10.3126/njog.v13i3.23507

\begin{abstract}
Aim: To estimate the severity of neonatal and maternal morbidity associated with instrumental vaginal delivery (IVD).

Methods: Record based cross-sectional retrospective study of 80 instrumental vaginal deliveries during two years from 2013 to 2015 were performed. Variables studied were neonatal and maternal complications.

Results: Out of 80 IVD, 19(23.8\%) were forceps deliveries and 61(76.2\%) were vacuum deliveries. The mean one minute Apgar score was 6 and 7 for forceps and vacuum delivery respectively. The five minute Apgar score for the both IVD was 8. Regarding maternal complications $7(8.75 \%$ ) cases had extended episiotomy with deep vaginal tears. In forceps delivery 5 had deep vaginal tear and one each for primary post-partum hemorrhage and urinary retention but among the vacuum deliveries two had deep vaginal tear only. Regarding neonatal complications, one had subgaleal bleed in forceps delivery and one had cephalhematoma with Erbs palsy in vacuum delivery.
\end{abstract}

Conclusions: The neonatal and maternal complications between both types of IVD were comparable. Forceps and repeated vacuum application resulted in low one minute Apgar score; and extended episiotomy and deep vaginal tear were associated with use of forceps

Key words: instrumental vaginal delivery, maternal morbidity, neonatal morbidity, outcome.

\section{INTRODUCTION}

Globally, about $10-20 \%$ of all deliveries need some form of assistance or intervention at delivery and $6-12 \%$ of these interventions are by instrumental vaginal deliveries. ${ }^{1}$ Vacuum extraction and forceps are the two options when an instrument is needed to facilitate a vaginal birth. It is a service provided in both basic and comprehensive essential (or emergency) obstetric care. ${ }^{2}$ The judicious use of instrumental vaginal delivery (IVD) has to great extent helped to reduce maternal mortality as well as perinatal mortality. ${ }^{3}$ Despite this, the practice of IVD has progressively been declining. The increased caesarean section (CS) rate, however, has limited the practice of IVD, partly because fewer women reach the second stage of labor and partly because CS is used as an alternative to IVD. ${ }^{4}$ In this present day, when there is a universal concern regarding the alarming rise of caesarean section rates, a study of such kind can be of help. The objective of the study is to estimate the severity of neonatal and maternal morbidity associated with IVD. This in turn can facilitate recommending the use of IVD to minimize LSCS in resource poor country like Nepal.

\section{CORRESPONDENCE}

Dr Basant Lamichhane

Department of Obstetrics \& Gynecology

Rapti Academy of Health Sciences, Ghorahi, Dang, Nepal

Email: 1cbasant@gmail.com

Phone: +977-9849157409

\section{METHODS}

A cross-sectional retrospective study was conducted. The study was based on records of the patients who had undergone instrumental vaginal delivery in a term singleton pregnancy from 15 April 2013 to 15 April 2015. The records were traced from record section of Patan Hospital at Patan Academy of Health Sciences. The neonatal and maternal complications following instrumental vaginal delivery were noted. Neonatal variables included sex, weight, Apgar score at $1 \& 5$ minutes; and complications like scalp laceration, intracranial hemorrhage, nerve injury, neonatal jaundice, need of phototherapy and neonatal mortality. The maternal variables were injury of perineum (extended episiotomy, $3^{\text {rd }}$ or $4^{\text {th }}$ degree perineal tear), hematoma, postpartum hemorrhage, puerperal sepsis, maternal mortality, age, parity, period of gestation, and indication of instrumental delivery. Most of the instrumental deliveries were conducted by specialist and few were performed by residents under supervision of the specialist. Approval from the institutional review board of Patan Academy of Health Sciences was taken. 


\section{RESULTS}

Out of 9705 deliveries over 2 years, 72 were vacuum deliveries and 27 were forceps deliveries. Out of total 99 instrumental deliveries conducted, records of 80 patients were available. Therefore study has included 80 cases in the study. Out of 80 IVD, 19(23.8\%) were forceps delivery and $61(76.2 \%)$ were vacuum deliveries. The ratio of forceps to vacuum was 1:4. Of the 19 cases of forceps 5 cases were forceps delivery following repeated use of vacuum application.

The mean maternal age for the IVD was 26 years. The mean POG for the IVD in the study was 39 weeks. The indication for the operative delivery was similar between both types of IVDs and maternal exhaustion was the leading cause of operative vaginal delivery. The weight of the babies delivered ranged from 2500 gm to $4400 \mathrm{gm}$ and two babies were over $4 \mathrm{~kg}$.

The mean APGAR 1 score was 6 and 7 for forceps and vacuum delivery respectively. The APGAR2 for the both IVD was similar i.e. 8. APGAR1 score less than 4 were noted in 3 vacuum deliveries and 1 forceps delivery. Regarding maternal complications $7(8.75 \%)$ cases had extended episiotomy with deep vaginal tears. Of the 7 cases $2(28 \%)$ were following vacuum delivery and $5(72 \%)$ were following forceps application. Out of 5 forceps applied $3(60 \%)$ were following sequential application of vacuum. One case had post-partum hemorrhage following forceps application. The $3(3.75 \%)$ cases following vacuum deliveries had puerperal pyrexia. Out of 3 cases 2 had episiotomy site infection and 1 had urinary tract infection (UTI). One case had urinary retention following forceps delivery.

Regarding fetal outcome 1 case following vacuum delivery had cephalhematoma with Erbs palsy and had uneventful recovery following 10 days of NICU care and phototherapy was required. Similarly 1 case following forceps delivery had subgaleal bleed for which phototherapy as well as exchange transfusion was required. Out of 4 cases of neonatal sepsis following IVD, 3 had undergone vacuum delivery and 1 was a forceps delivery. However no neonatal death and maternal mortality were associated with IVD.

\section{DISCUSSION}

This study was performed to estimate the neonatal and maternal morbidity associated with forceps and vacuum delivery. According to the study no significant results related to maternal morbidity and fetal complications were noted. However the study has definitely shown relatively low APGAR1 score with forceps and also increase rate of episiotomy extension and deep vaginal tear along with use of forceps for failed vacuum.

The rate of instrumental delivery in the study was 1.12 $\%$ which is comparable to other developing countries of Africa. ${ }^{5,6}$ The percentage of IVD of the study is much lower as compared to $16 \%$ in Canada, $11 \%$ England, 10\% USA, 14\% Australia, 10\% Denmark. ${ }^{7}$ On the other hand the rate of LSCS of the study was $42.04 \%$. Despite application of IVD has been listed as a component of basic and comprehensive emergency operative care, the trend of its use has progressively been disappearing. ${ }^{8}$ The likely possible explanation to such trend could be the fear of its use in regards to neonatal and maternal complication. The other reason could be increasing rate of caesarean delivery. Along with increasing caesarean rate there are few cases reaching second stage of labor and therefore decreasing the chances of instrumental application. This trend has also influenced the learning opportunity and mastering the art among new practitioners and residents.

There have been various studies which have revealed various neonatal and maternal complication following IVD. As per Caughey et al perineal injuries like $2^{\text {nd }}$ and $3^{\text {rd }}$ degree tear have been shown to more associated with forceps. ${ }^{9,10}$ Whereas study by Parpas et al and the current study shows no significant difference between the type of IVD. ${ }^{11}$ Similar to the study by Gardella et al, the current study has also shown the increase rate of maternal morbidity and low APGAR along with sequential use of vacuum and forceps application. ${ }^{12}$ RCOG therefore recommends that the operator must balance the risks of caesarean section following failed vacuum delivery with the risks of forceps delivery following failed vacuum extraction. ${ }^{13}$ The choice of instrument may be influenced by clinical circumstances, operator choice and availability of specific instruments. ${ }^{14}$

Regarding neonatal complication along with IVD is trauma which includes scalp edema, nerve injury, abrasion, cephalhematoma and fractures. These complications generally disappear by hours or a weeks and neonatal complications are extremely uncommon in both procedure. ${ }^{15}$ This study has shown neonatal complications in $2.5 \%$ cases only. 


\section{CONCLUSIONS}

The neonatal and maternal complications between both types of IVD were comparable. The judicious use of either of the instrument by a skilled operator is safe both in terms of neonatal and maternal outcome. There was low one minute Apgar score with forceps especially in failed vacuum; and maternal morbidities like extended episiotomy and deep vaginal were also increased with forceps delivery. To validate this result requires a larger multicentric study.

Conflicts of Interest: None

\section{REFERENCES}

1. Onoh RC, Ezeonu PO, Chijioke O, Onoh TP, Saidu AK, Ezeonu CT. Disappearing art of forceps delivery and the trend of instrumental vaginal deliveries at Abakaliki, Nigeria. Afr J Med Health Sci. 2014;13:99-104

2. WHO, UNICEF. Guidelines for monitoring the availability and use of obstetric services. New York: WHO, UNICEF, 1997.

3. Bale JR, Stoll BJ, Lucas AO, editors. Improving Birth Outcomes: Meeting the Challenge in the Developing World Washington (DC): National Academies Press (US); 2003

4. Ameh $\mathrm{C}$, Weeks A. The role of instrumental vaginal delivery in low resource settings. BJOG: An International Journal of Obstetrics \&Gynaecology. 2009;116:22-5.

5. Onoh RC, Ezeonu PO, Chijioke O, Onoh TP, Saidu A K, Ezeonu CT. Disappearing art of forceps delivery and the trend of instrumental vaginal deliveries at Abakaliki, Nigeria. Afr J Med Health Sci. 2014;13:99-104

6. Kadas AS, Alliyu LD, Hauwa MA. Instrumental delivery in Bauchi, Northeast Nigeria; J West Afr College Surg. 2011;1(4):18-27

7. Noton F. International difference in the use of obstetric interventions. JAMA. 1990;263(24):3286-91.

8. Lamichhane B, Singh A. Changing trends of instrumental deliveries at Patan Hospital. NJOG. 2015;20(2):33-5.
9. Caughey AB, Sandberg PL, Zlatnik MG, Thiet MP, Parer JT, Laros RK. Forceps compared with vacuum: rates of neonatal and maternal morbidity. Obstet Gynecol. 2005; 106:908-12.

10. Johnson JH1, Figueroa R, Garry D, Elimian A, Maulik D. Immediate maternal and neonatal effects of forceps and vacuum-assisted deliveries. Obstet Gynecol. 2004;103(3):5138

11. Prapas N, Kalogiannidis I, Masoura S. Operative vaginal delivery insingleton term pregnancies: short term maternal and neonatal outcomes. Hippokratia. 2009;13:41-5

12. Gardella C, Taylor M, Benedetti T, Hitti J, Critchlow C. The effect of sequentialuse of vacuum and forceps for assisted vaginal delivery on neonatal andmaternal outcomes. Am J Obstet Gynecol. 2001;185:896-902.

13. Royal College of Obstetricians and Gynecologists. Operative vaginal delivery (Guideline 26). [Cited 2015 August 1]. URL https://www.rcog.org.uk/en/guidelinesresearch-services/ guidelines/gtg26/

14. O'Mahony F, Hofmeyr GJ, Menon V. Choice of instruments for assisted vaginal delivery. Cochrane Database of Systematic Reviews. 2010;11(CD005455). DOI:: 10.1002/14651858. CD005455.pub2.

15. Bailey PE. The disappearing art of instrumental delivery: time to reverse the trend. Int J Gynecol Obstet 2005;91:89-96. 